\title{
ACTIVE POWER AND CURRENT CONTROL FOR A MODULAR MULTILEVEL CONVERTER (MMC) BASED SYSTEM
}

\author{
Gayithri C', R S Geetha ${ }^{2}$ \\ ${ }^{1} P G$ Scholar, Dept of Electrical and Electronics, BMS College of Engineering, Karnataka, India \\ ${ }^{2}$ Associate Professor, Dept of Electrical and Electronics, BMS College of Engineering, Karnataka, India
}

\begin{abstract}
Modular Multilevel Converter (MMC) has found very wide application in renewable energy sources, DC power transmission, high voltage applications and micro grid. However the technical challenge of MMC is to maintain constant current, constant power and constant voltage at the output depending on the requirement. In this paper a control loop is developed for maintaining constant power at the MMC. The power controller is realized by using PI controller. The PWM technique used for generation of gating pulses is Phase Disposition PWM (PD-PWM) technique, The simulation of current and the active power controller is carried out by MATLAB/SIMULINK and the results are presented.
\end{abstract}

Keywords: Modular Multilevel Converter (MMC), Phase Disposition PWM (PD-PWM) technique, Proportional Integral (PI) controller, Current controller, Sub Module (SM), and Active power controller.

\section{INTRODUCTION}

The MMC has found very wide application in High Voltage DC (HVDC) power transmission, renewable energy sources, and micro grids. The other well known topology is multilevel topology, But it as few disadvantages such as it can be used only in medium voltage application, The number of components required increases as the voltage level increases and number of the circuit components increase proportional to the power capacity. Compared to multilevel converter MMC has few advantages such as:

- Harmonic distortion is found to be very less, due to increased number of voltage levels compared to that of a multilevel converter.

- MMC circuit configuration is very simple compared to multilevel converter.

- Even when few of the sub modules are out of order, the MMC can remain in operating state.

- DC link current and arm current is found to be continuous in MMC, hence the DC link capacitor can be omitted [1].

\section{MODULAR MULTILEVEL CONVERTER}

\section{(MMC)}

Fig-1, shows the MMC circuit that is considered for simulation studies in this paper. It consist of six valves each connecting one AC terminal and one DC terminal. Each valve consists of a number of sub modules and each sub module is a two level converter consisting of IGBTs connected in series across the capacitor, with the midpoint connection and one of the two capacitor terminals brought out as external connections. The sub module can be either half bridge or full bridge configuration. With a suitable number of sub modules connected in series, the valve can synthesize a stepped voltage waveform that approximates very closely to a sine-wave and contains very low level of harmonic distortion. The MMC differs from other types of converter in that, current flows continuously in all six valves of the converter throughout the cycle. The direct current splits equally into the three phases and the alternating current splits equally into the upper and lower valve of each phase. The current in each valve is therefore, related to the direct current $\mathrm{I}_{d}$ and alternating current $\mathrm{I}_{\mathrm{ac}}$ as follows [2].

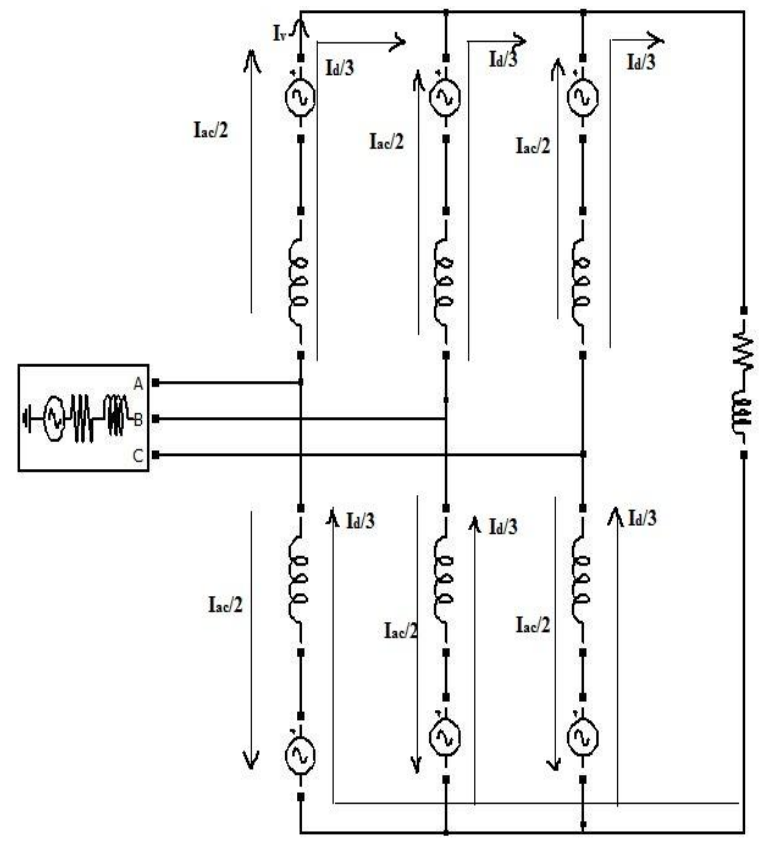

Fig-1: Three-phase MMC.

Upper valve

$$
\mathrm{I}_{\mathrm{v}}=\mathrm{I}_{\mathrm{d}} / 3+\mathrm{I}_{\mathrm{ac}} / 2
$$


Lower valve

$$
\mathrm{I}_{\mathrm{v}}=\mathrm{I}_{\mathrm{d}} / 3-\mathrm{I}_{\mathrm{ac}} / 2
$$

Where, $I_{v}=$ valve current

$\mathrm{I}_{\mathrm{d}}=$ direct current

$\mathrm{I}_{\mathrm{ac}}=$ alternating current

PI based controllers are developed for constant DC voltage as well as constant DC power for load variation. In this regard a PI controller based power controller for MMC is developed in this paper. The overall control scheme also involves a current controller, which gets the input signal from the power controller [3].

In this paper, half bridge configuration of sub module is used to build MMC for controlling the current and active power.

3. GATE PULSE GENERATION FOR MMC USING PD-PWM METHOD

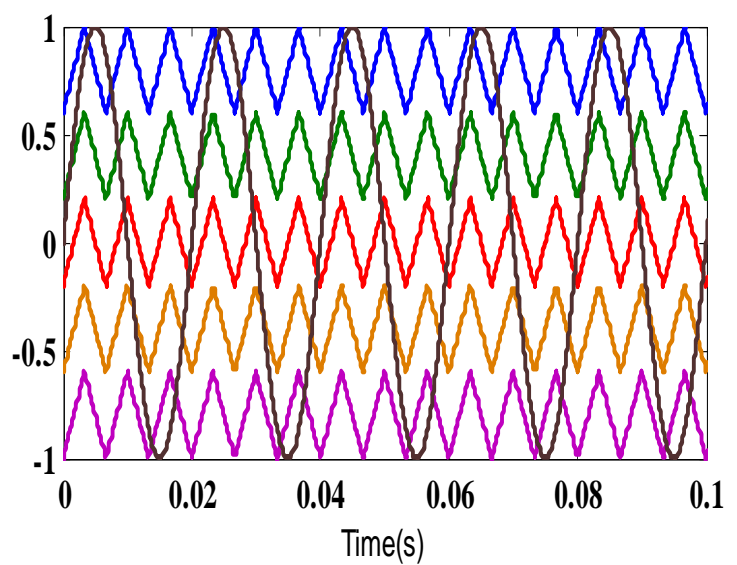

Fig-2: PD-PWM method waveform for 6level MMC.

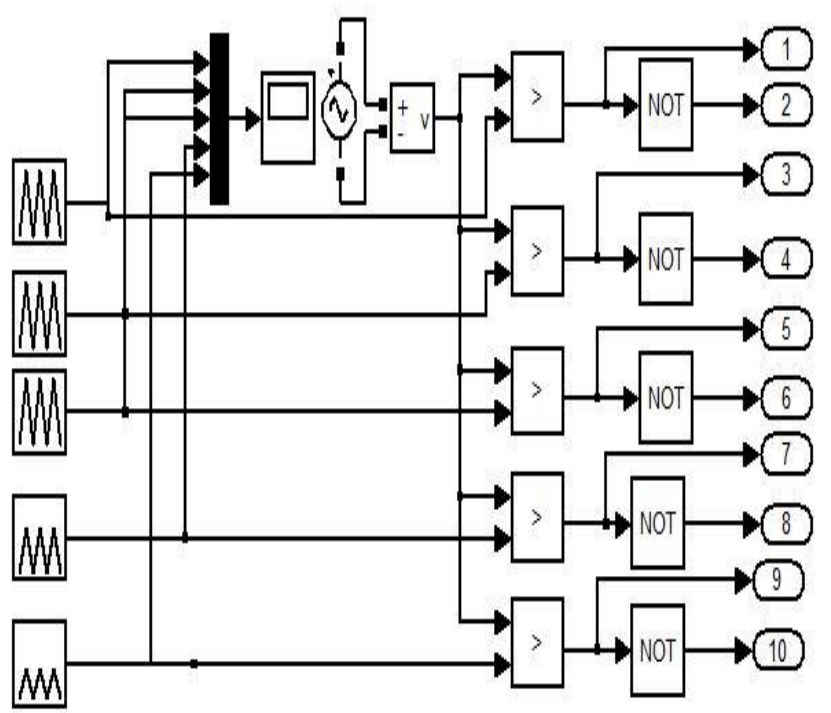

Fig-3: Simulation model of PD-PWM method for 6 level MMC.
In PD-PWM method all carrier waveforms are in phase. As shown in Fig-2, here a-phase modulation signal is compared with $\mathrm{N}-1$ triangle waveforms, where $\mathrm{N}$ is the number of levels Here Fig-3, shows the simulation model implemented for 6 level MMC [4].

\section{ACTIVE POWER AND CURRENT CONTROLLER}

The aim of the active power controller is to maintain a constant active power at the reference value. The block diagram of active power controller is shown in Fig-4, where the current controller is in the inner loop of active power controller [5].

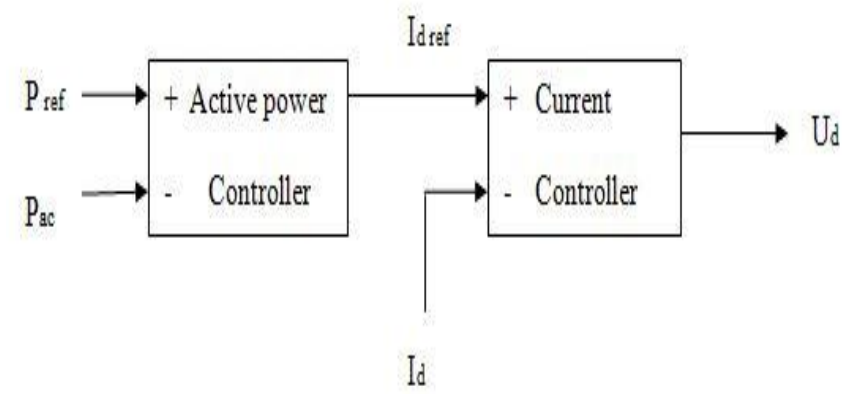

Fig-4: Block diagram of active power controller.

Fig-5, shows the active power controller where the reference active power $\mathrm{P}_{\text {ref }}$ is fixed, the measured power $\mathrm{P}_{\mathrm{ac}}$ is compared with $\mathrm{P}_{\text {ref }}$, difference is given to a PI controller which controls the active power.

The Fig-6, shows the d component of current controller here the current is controlled by using a PI controller, the output of the PI controller is summed with the voltages as shown in Fig-5, thus the modulating reference voltage of $\mathrm{d}$ component is obtained [1].

Fig-7, shows the q component of current controller, where the q component of current is controlled similar to that of the d component.

The current controller is placed inside the power controller loop for the control of active power.

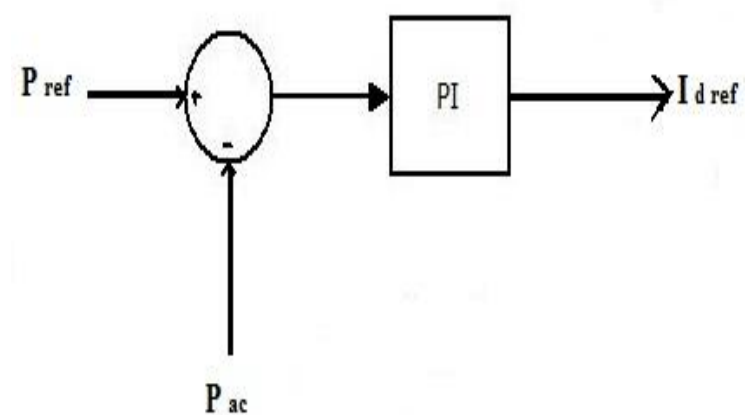

Fig-5: Active power controller. 


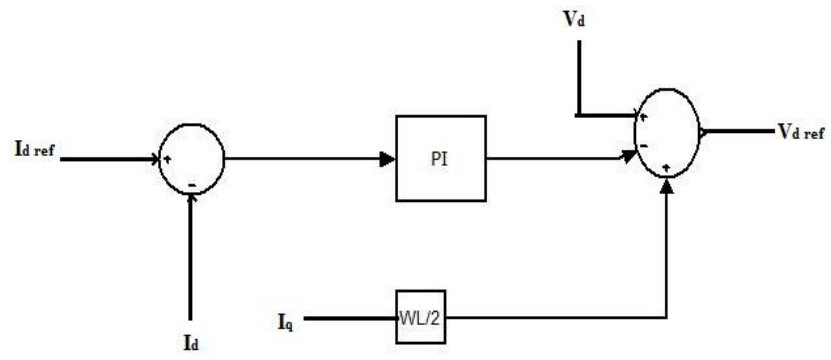

Fig-6: $I_{d}$ current controller.

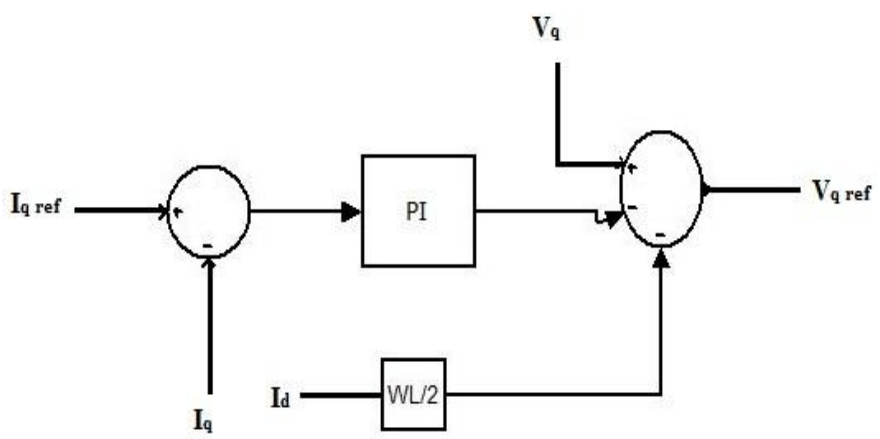

Fig-7: $I_{q}$ current controller.

As seen from the Fig-5, Fig-6 and Fig-7, PI controller plays a vital role for the control of active power and current. Hence it is necessary to find accurate values of $\mathrm{K}_{\mathrm{p}}$ and $\mathrm{K}_{\mathrm{i}}$ for the active power and the current controller. The rating of the system is chosen and the set of equations used for finding the initial values of $\mathrm{K}_{\mathrm{p}}$ and $\mathrm{K}_{\mathrm{i}}$ are given below:

AC supply voltage : $3000 \mathrm{kV}$ (L-L rms)

$\mathrm{P}_{\mathrm{dc}}=10 \mathrm{kw}$

$$
\begin{array}{rl}
\mathrm{P}=3 / 2 & * \mathrm{~V}_{\mathrm{b}} \mathrm{I}_{\mathrm{b}} \\
\mathrm{V}_{\mathrm{ac}} & =\mathrm{mV}_{\mathrm{dc}} / 2
\end{array}
$$

$\mathrm{V}_{\mathrm{ac}}$ is the peak phase voltage

$$
\begin{aligned}
& \mathrm{P}_{\mathrm{dc}}=3 / 2 * \mathrm{~V}_{\mathrm{b}} \mathrm{I}_{\mathrm{b}}=\mathrm{V}_{\mathrm{dc}} \mathrm{I}_{\mathrm{dc}} \\
& \mathrm{Z}_{\text {base }}=\mathrm{V}_{\mathrm{b}} / \mathrm{I}_{\mathrm{b}} \Omega \\
& \mathrm{L}_{\text {base }}=\mathrm{Z}_{\mathrm{b}} / \mathrm{W}_{\mathrm{b}} \mathrm{H}
\end{aligned}
$$

$\mathrm{K}_{\mathrm{p}}=0.524$

$\mathrm{K}_{\mathrm{i}}=0.1483$

Where, $\mathrm{P}_{\mathrm{dc}}=\mathrm{dc}$ power output

$\mathrm{V}_{\mathrm{dc}}=\mathrm{dc}$ voltage

$\mathrm{P}=\mathrm{ac}$ power input
$\mathrm{V}_{\mathrm{b}}=$ base voltage

$\mathrm{I}_{\mathrm{b}}=$ base current

$\mathrm{m}=$ modulation index

$\mathrm{Z}_{\text {base }}=$ base impedance

$\mathrm{R}_{\text {base }}=$ base resistance

$\mathrm{L}_{\text {base }}=$ base inductance

$\mathrm{R}_{\mathrm{pu}}=$ resistance in $\mathrm{pu}$

$\mathrm{T}_{\mathrm{i}}=$ integral time constant

$\mathrm{T}_{\mathrm{a}}=$ average time

$\mathrm{K}_{\mathrm{p}}=$ proportional gain

$\mathrm{K}_{\mathrm{i}}=$ integral gain

The initial values of $\mathrm{K}_{\mathrm{p}}$ and $\mathrm{K}_{\mathrm{i}}$ are adjusted to get a good response.

\section{SIMULATION AND RESULTS}

The Fig-8, shows the simulation model of a MMC with current and active power controller.

Fig-9, and Fig-10, shows the performance of the current controller under steady state condition. Fig. 9, is the controlled $I_{d}$ current waveform for a reference current of 1pu. Fig-10, is the controller $I_{q}$ current waveform for a reference current of 0pu. Fig-11, shows the performance of the current controller under dynamic condition for a step change in the reference $I_{d}$ current, the controller is able to track the step change in the reference value with a time delay of $0.2 \mathrm{msec}$. Fig-12 and Fig-13, shows the $\mathrm{d}$ and $\mathrm{q}$ component of modulation index of the reference (modulating) voltage waveform.

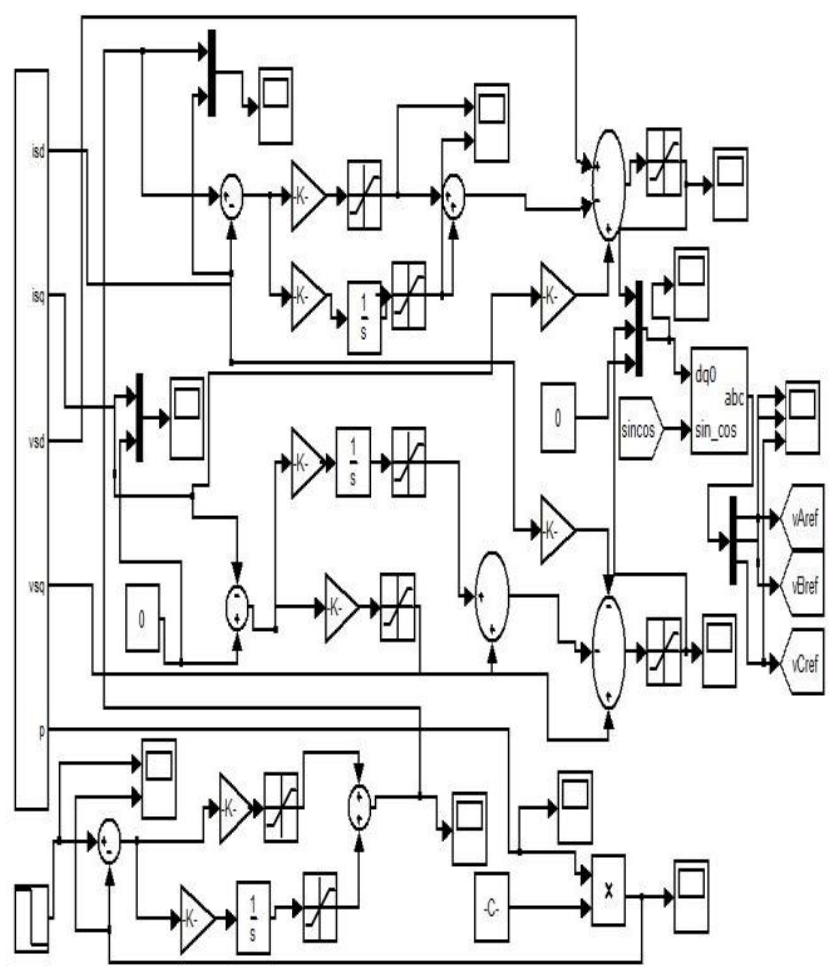

Fig-8: Simulation model of active power and current controller. 


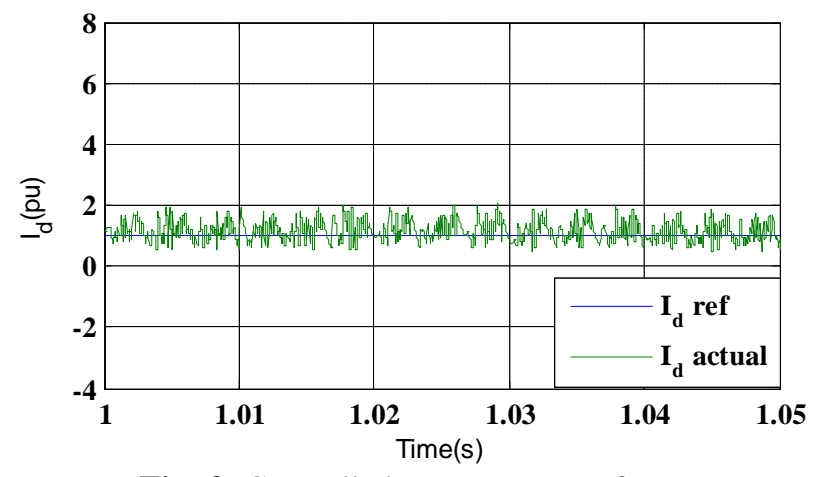

Fig- 9: Controlled $I_{d}$ current waveform.

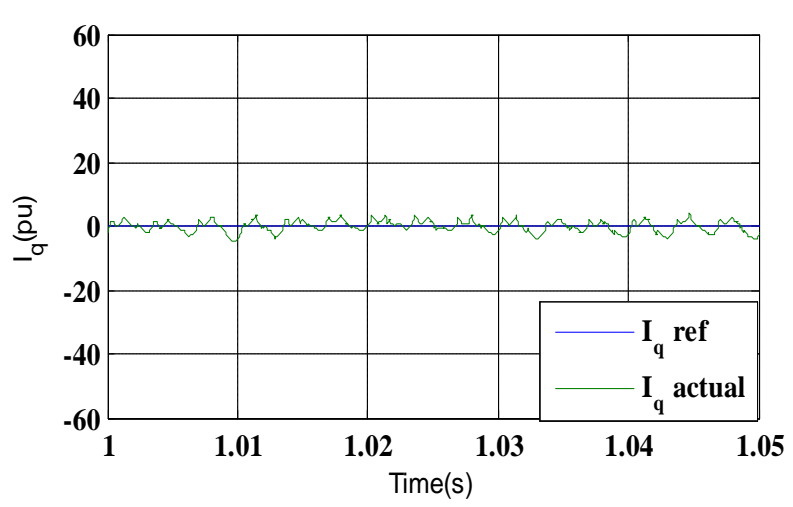

Fig-10: Controlled $\mathrm{I}_{\mathrm{q}}$ current waveform.

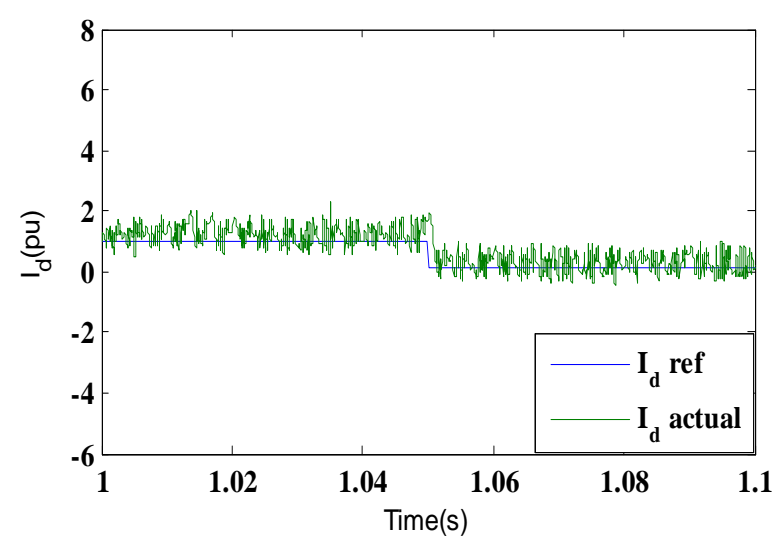

Fig-11: Controlled $I_{d}$ current waveform under dynamic condition.

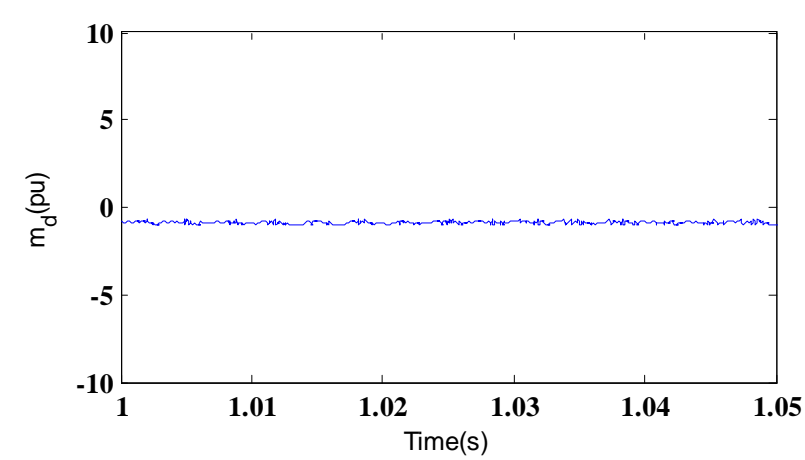

Fig-12: Modulation index of d component waveform

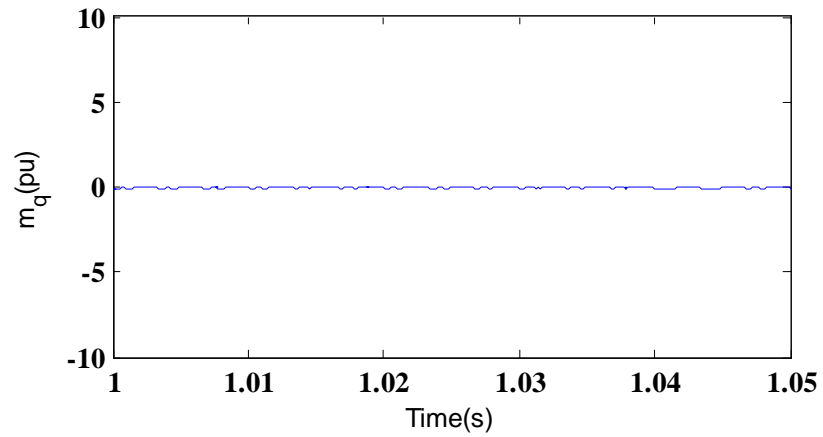

Fig-13: Modulation index of q component waveform.

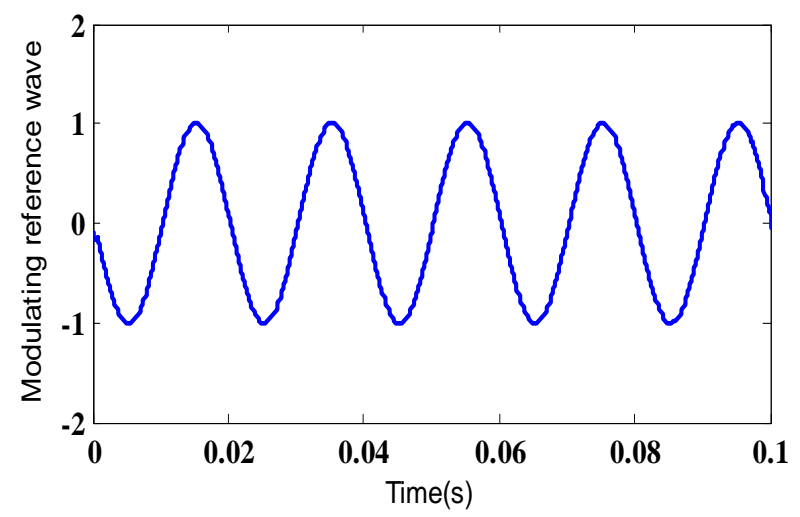

Fig-14: Modulating reference voltage waveform.

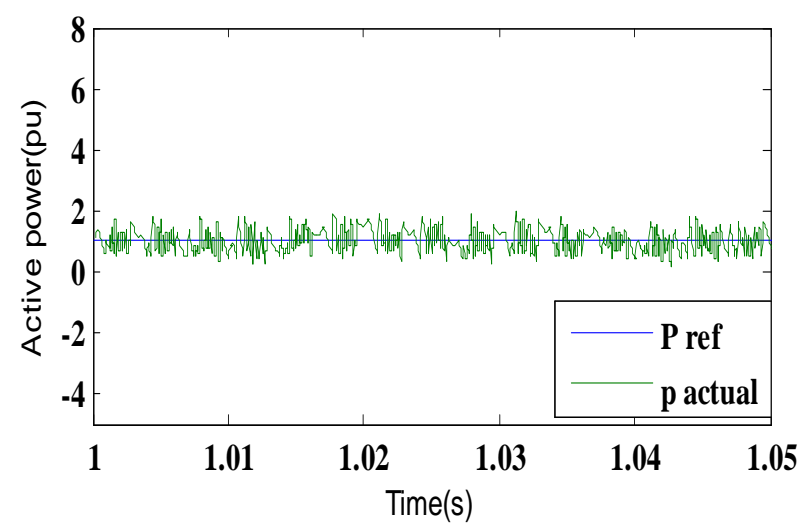

Fig-15: Controlled active power waveform.

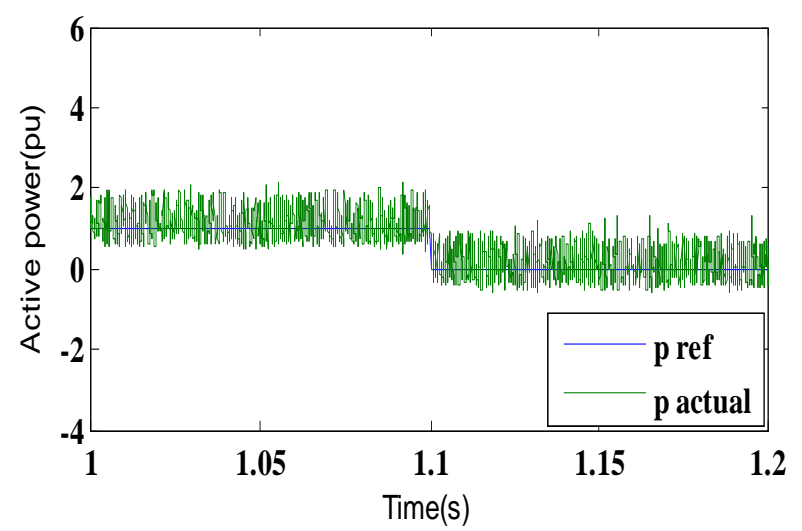

Fig-16: Controlled active power waveform under dynamic condition. 
Fig-14, shows the modulating reference voltage waveform generated. Fig-15, shows the performance of the active power controller waveform for a reference active power of 1 pu under steady state condition and the Fig-16, shows the performance of the active power controller under dynamic condition, that is for a step change in the reference active power the controller is able to track the step change in the reference value with a time delay of $0.2 \mathrm{msec}$.

\section{CONCLUSIONS}

In this work, the gating pulse generation for a MMC using PD-PWM technique is developed and the output of the MMC is observed. Controllers are developed by using PI controller for control of current and active power, the performance of the controller is verified under steady state and under dynamic condition, the controller is found to be working good and it is able to track the step change in the reference value with a time delay of $0.2 \mathrm{msec}$. The work can be further extended to implement reactive power controller.

\section{REFERENCES}

[1] ZHAO Yan, HU Xue-hao, TANG Guang-fu, HE Zhiyuan, "A study of MMC model and its current control strategies," China Electric Power Research Institute, Haidian District, Beijing China, 2nd IEEE International Symposium on Power Electronics for Distributed Generation Systems 2010

[2] Elisabeth Nokleby Abildgaard,"Exploring the properties of Modular Multilevel Converter based HVDC link," Master of Energy and Environmental Engineering, Department of Electric Power Engineering, Norwegian University of Science and Technology.

[3] Agrawal.S, Geetha R S, "Controllers for voltage source converters," Emerging trends in communication, control, signal processing and computing applications (C2SPCA), 2013 international conference on 10-11 Oct.2013

[4] Georgios S Konstantinou, Vassilios G Agelidis, "performance evaluation of half bridge cascaded multilevel converters operated with multicarrier sinusoidal PWM techniques," school of electrical and information engineering, The university of Sydney NSW 2006, Australia

[5] Wei LI, Luc-Andre Greigoire, Jean Belanger OPALRT technologies, "Control and performance of Modular Multilevel Converter System," Cigre Canada, Conference on power systems Halifax, September 6-8, 2011

\section{BIOGRAPHIES}

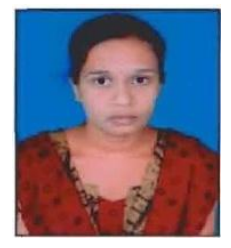

Gayithri.C received the B.E. degree in Electrical and Electronics Engineering from Dr.T.Thimmaiah Institute of Technology, VTU, Kolar Gold Fields, Karnataka India, in 2012, and is currently pursuing the M.Tech degree in Power Electronics from BMS College of Engineering, VTU,
Bangalore, Karnataka, India. Her research interests includes in the areas of Power Electronics, and HVDC.

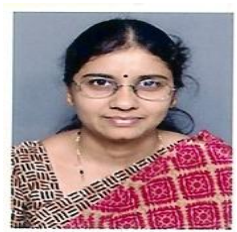

R.S.Geetha received the B.E. degree in Electrical Engineering in the year 1993 and M.E. degree in Power Electronics from Bangalore University in 1999. At present, she is working in the Department of Electrical and Electronics Engineering, BMS College of Engineering, Bangalore, Karnataka, India. She is pursuing her Ph.D. at the same institution. Her research interests are in the areas of Power Electronics, HVDC and FACTS. 